\title{
Commentary: System Expansion and Substitution in LCA: A Lost Opportunity of ISO 14044 Amendment 2
}

\author{
Matthias Finkbeiner* \\ Chair of Sustainable Engineering, Institute of Environmental Technology, Technische Universitaet Berlin, Berlin, Germany
}

Keywords: ISO 14044, LCA, life cycle assessment, allocation, system expansion

\section{A Commentary on}

System Expansion and Substitution in LCA: A Lost Opportunity of ISO 14044 Amendment 2 by Heijungs, R., Allacker, K., Benetto, E., Brandão, M., Guinée, J., Schaubroeck, S., et al. (2021). Front. Sustain. 2:692055. doi: 10.3389/frsus.2021.692055

\section{INTRODUCTION}

\section{OPEN ACCESS}

Edited and reviewed by: Mikołaj Owsianiak,

Technical University of Denmark, Denmark Mélanie Douziech, MINES ParisTech, PSL

University, France

*Correspondence: Matthias Finkbeiner matthias.finkbeiner@tu-berlin.de

Specialty section:

This article was submitted to

Quantitative Sustainability Assessment,

a section of the journal

Frontiers in Sustainability

Received: 22 June 2021 Accepted: 06 August 2021 Published: 30 August 2021

Citation:

Finkbeiner M (2021) Commentary: System Expansion and Substitution in LCA: A Lost Opportunity of ISO 14044 Amendment 2.

Front. Sustain. 2:729267. doi: 10.3389/frsus.2021.729267
Heijungs published recently together with seven co-authors an opinion paper in this journal titled "System Expansion and Substitution in LCA: A Lost Opportunity of ISO 14044 Amendment 2" (Heijungs et al., 2021). Their contribution makes mainly two points:

- According to their interpretation, the 2nd amendment of ISO 14044 (ISO 14044, 2020) "effectively rules out [actual system expansion and] prescribes that expanding the system to include additional functions must be understood as subtracting avoided burdens with the substitution method."

- The amendment has failed to bring the clarification, that "the LCA community has been eagerly looking forward to [... to a largely confusing hierarchy to address the multi-functionality issue."

This reply intends to clarify, that the first of these points is based on an erroneous interpretation of the standard, respectively, amendment and that the second point is based on a misunderstanding of the global, stakeholder-oriented standardization process at ISO.

\section{INTERPRETATION OF ISO 14044 AMENDMENT 2}

The proper interpretation of International Standards (ISO) requires an understanding of the specific language and coding rules, which apply to them. While they are ideally as understandable as possible for as many stakeholders as possible, a certain knowledge of the standard language and rules is necessary to decipher them correctly. While these codes and norms may appear to some as superfluous and misleading at first sight, they have the same justification as other formal codes like e.g., mathematics, legislative language, or the language of certificates of employment. Languages in such contexts may appear also difficult to understand at first sight. As a consequence, they are sometimes not interpreted correctly, especially when taken literally, while they are crystal-clear for those in the know.

The first main conclusion of Heijungs et al., i.e., the interpretation of the Amendment 2 as being prescriptive for only allowing system expansion as substitution (avoided burden) and 
therefore restricting what they call "actual system expansion" is based on the following text in the standard: "Therefore, the product system that is substituted by the co-product is integrated in the product system under study. In practice, the co-products are compared to other substitutable products, and the environmental burdens associated with the substituted product(s) are subtracted from the product system under study." It is correct, that basically this whole section focusses on this particular option for system expansion. When taken separately and when read as colloquial language, this may lead to the impression of Heijungs et al., but there are several standardization aspects that make it crystal-clear, that such an interpretation is not correct:

1. An amendment has to be read together with the main body of the standard (ISO 14044, 2006). It does not replace the content of the amended standard, it adds to it. Therefore, as Heijungs et al. point out by themselves, the generic system expansion clauses are introduced in the beginning of the amendment. They are still valid and the amendment just adds to it, it does not replace it.

2. ISO has in their Directives clear rules, that certain verbal expressions have to be used to identify the normative content of the standard, i.e., "shall" for requirements, "should" for recommendations, "may" for permissions and "can" for possibilities (ISO, 2021a). The text referred to by Heijungs et al. does not include any of these verbal forms, i.e., it can never have any binding meaning or even overrule the "shalls" and "shoulds" in the main body of the text. It is purely a description, that is not normative at all.

3. The Amendment is an informative Annex. If an Annex is qualified in the heading as "informative," this is an obvious indication, that its clauses (here: the Amendment) cannot be interpreted in changing any of the existing requirements of the associated standard (here: ISO 14044). Annexes are used to provide additional information to the main body of the document, e.g., by presenting information regarding a particular application of the document. There are also normative annexes, which provide additional normative text to the main body of the document, but informative annexesas the one relevant here-are not normative at all. As such, an informative annex can never change the actual content or interpretation of the standard.

The actual intention of these clauses in the amendment was the consensus, that it should be clarified, that the "subtraction approach" can also be used as system expansion as is commonly done in LCA practice. This was always the intention as originally documented by ISO 14041 (1998) as Heijungs et al. point out as well. However, recently there were some scholars from the academic world, who were arguing that the "subtraction approach" is not covered by system expansion according ISO or that system expansion altogether would only belong to particular types of LCA. Therefore, the amendment clarifies, that system expansion is applicable for all types of LCA and that the "subtraction approach" is covered by the requirements for system expansion in ISO 14044.
It was never the intention to make it the only option, it was the intention to clarify, that it is one of the options. This is properly reflected by the text of the amendment, if the standardization rules and language are considered. In a nutshell, the allocation annex of Amendment 2 did not include any changes to the requirements and recommendations of ISO 14044 when it comes to allocation as this is not possible by an informative annexper definition. As such, contrary to their interpretation, the Amendment 2 fully satisfies the request of Heijungs et al. to have both options for dealing with system expansion.

For the second topic, "the lost opportunity" for clarification of the multi-functionality issue, there is a common misunderstanding about the international standardization process. Standards are sometimes criticized by some stakeholders (especially from academia) for not being specific enough on certain issues. There are some scholars with strong convictions in certain topics, even though they are value choices, like e.g., allocation. They typically come from a rather theoretical background.

There is the famous quote of unclear source: "In theory there is no difference between theory and practice, while in practice there is." Standards are for practice, not for academic theory. They represent the global consensus on those methodological features for which such a consensus exists. More specific stipulations on, e.g., allocation procedures or a default set of impact categories, let alone a particular impact assessment method might be desired by some stakeholders, but there is no global stakeholder consensus on them. It is a very democratic procedure to develop an ISO standard, but democracy does not guarantee that the outcome is to the liking of everyone. Standards do not have specific authors, they are collaboratively written by often hundreds of people, who provide comments as member of the working groups or as member of the national mirror committees that provide input to the standard development. It makes no sense to blame the standards or those involved in the standardization process for this, as it is the natural result of such a process, that there is no "a one size fits all-LCA" and that the final text is a compromise.

ISO standards respond to a need in the market (Finkbeiner, 2014). While academic debates are dominated by the providers of LCA, standards need to focus on the users of LCA. While Heijungs et al. qualify the ISO hierarchy for multi-functional processes as "largely confusing," many users seem to be able to work with this hierarchy without any show-stopping problems. Many users identified proper ways, how they handle this within their sector or for their products. At least, it was not confusing enough for them to agree on a change of this hierarchy.

ISO standards are based on global expert opinion (Finkbeiner, 2014). ISO standards are developed by groups of experts from all over the world and standards should not target the 5\% most advanced users, but the whole world. As such, while some leading experts in the developed world may feel, it is time, that their ideas are reflected in a standard, many other parts of the world may have just started to understand and implement the more established practice documented in the standard. While established practice starts to get traction, they are not keen to switch to the latest trend in LCA science immediately. 
ISO standards are developed through a multi-stakeholder process and ISO standards are based on a consensus (Finkbeiner, 2014). This means, they are not primarily about being theoretically right and academically advanced. They are a compromise of a democratic consensus building process and not about academic dogmatism.

\section{CONCLUSION}

The take-home message of this reply for LCA practitioners is, that they can still do system expansion according to ISO 14044 both ways-by adding additional functions or by subtracting additional functions. The interpretation by Heijungs et al. that Amendment 2 is supposed to restrict the use of "actual system expansion" in any way is a misunderstanding and therefore not correct.

Anyone envisioning future revisions of ISO 14044 can contribute to the process, but understanding the standardization process and its rules is important to manage expectations. Standards are not necessarily about academic excellence.

\section{REFERENCES}

Finkbeiner, M. (2014). "The international standards as the constitution of life cycle assessment: the ISO 14040 series and its offspring," in Background and Future Prospects in Life Cycle Assessment. LCA Compendium - The Complete World of Life Cycle Assessment, ed W. Klöpffer (Dordrecht: Springer), 85-106. doi: 10.1007/978-94-017-8697-3_3

Heijungs, R., Allacker, K., Benetto, E., Brandão, M., Guinée, J., Schaubroeck, S., et al. (2021). System expansion and substitution in LCA: a lost opportunity of ISO 14044 Amendment 2. Front. Sustain. 2:692055. doi: $10.3389 /$ frsus.2021.692055

ISO (2021a). ISO/IEC Directives, Part 2, Principles and Rules for the Structure and Drafting of ISO and IEC Documents. 9th edn. Geneva: International Organization for Standardization.

ISO (2021b): Standards. Available online at: https://www.iso.org/standards.html (accessed June 22, 2021)

ISO 14041 (1998). Environmental Management. Life Cycle Assessment. Goal and Scope Definition and Inventory Analysis. 1st edn. Geneva: International Organization for Standardization.

ISO 14044 (2006). Environmental Management. Life Cycle Assessment. Requirements and Guidelines. 1st edn. Geneva: International Organization for Standardization.
According to ISO (2021b), "standards are the distilled wisdom of people with expertise in their subject matter and who know the needs of the organizations they represent-people such as manufacturers, sellers, buyers, customers, trade associations, users or regulators." While it is acknowledged that some respected academic colleagues see the completed Amendment 2 as a "lost opportunity," the actual target audience of the standards is apparently of a different opinion as the amendment was approved almost unanimously with $93 \%$ positive votes.

\section{AUTHOR CONTRIBUTIONS}

MF drafted and edited the text.

\section{FUNDING}

There was no third-party funding provided for this paper, but the support by the Open Access Publication Fund of TU Berlin is acknowledged.
ISO 14044 (2020). Environmental Management. Life Cycle Assessment. Requirements and GuiISOdelines. Amendment 2. Geneva: International Organization for Standardization.

Conflict of Interest: The author declares that the research was conducted in the absence of any commercial or financial relationships that could be construed as a potential conflict of interest.

Publisher's Note: All claims expressed in this article are solely those of the authors and do not necessarily represent those of their affiliated organizations, or those of the publisher, the editors and the reviewers. Any product that may be evaluated in this article, or claim that may be made by its manufacturer, is not guaranteed or endorsed by the publisher.

Copyright (c) 2021 Finkbeiner. This is an open-access article distributed under the terms of the Creative Commons Attribution License (CC BY). The use, distribution or reproduction in other forums is permitted, provided the original author(s) and the copyright owner(s) are credited and that the original publication in this journal is cited, in accordance with accepted academic practice. No use, distribution or reproduction is permitted which does not comply with these terms. 